\title{
Development and Design Optimisation of a Small Floating Hydroelectric Power Plant
}

\author{
Tomas Kalina $^{1}$, Ladislav Illes ${ }^{2}$, Martin Jurkovic ${ }^{1 *}$, \\ Vladimir Luptak ${ }^{3}$
}

${ }^{1}$ The Faculty of Operation and Economics of Transport and Communications, University of Zilina, Univerzitna 1, 01026 Zilina, Slovakia;

tomas.kalina@fpedas.uniza.sk,martin.jurkovic@fpedas.uniza.sk

${ }^{2}$ MULTI Engineering Services, Dunajske nabrezie 4726, 94501 Komarno, Slovakia; ladislav.illes@multi.engineering

${ }^{3}$ Department of Transport and Logistics, Faculty of Technology, Institute of Technology and Business in Ceske Budejovice, 37001 Ceske Budejovice, Czech Republic; luptak@mail.vstecb.cz

Abstract: This study deals with the research and development of the optimal design of a small floating hydroelectric power plant by theoretical analysis and the subsequent conceptual design of the optimal variant. A computational fluid dynamics (CFD) system is used for theoretical analyses of flow, flow around, free surface properties, and motion of bodies in the water. The aim of this study is to identify the optimal geometry and construction of a small floating hydroelectric power plant. In the study, five different versions of floating pontoons are designed and analysed in the first phase. CFD analysis is used to determine the choice of the most suitable concept, which is further modified based on the calculation results. The result of the study is the design of a suitable design solution, which obviously achieves higher efficiency compared to a conventional water wheel. Finally, the further direction of research is presented, with a focus on maximising the performance and further optimisation of the small floating hydroelectric power plant structures.

Keywords: optimisation; power plant; computational fluid dynamics (CFD); water wheel; hydraulic power

\section{Introduction}

Hydropower plants are powerful tools for reducing greenhouse gas emissions. There are several perspectives on the efficiency of hydropower plants and on the process of building them in order to generate electricity from renewable sources [1]. For this purpose, large waterworks are being built, including hydropower 
plants, which, however, are not currently operating efficiently and it is, therefore, necessary to modernise and rebuild them to operate more efficiently [2].

In addition, the impact of hydropower plants on the ecosystem is negative [3]. Another approach is to build small hydropower plants, which are often also questioned for several reasons [4]. The most significant problem in building small hydropower plants is the major intervention in the natural river flow. This is most often achieved by completely damming the flow. This maximises the potential of the flow, but has several negative effects. Such negative effects can only be eliminated by a partial damming of the stream, which makes it possible to preserve, at least partially, the natural state of the riverbed. Small hydropower plants can therefore cause serious damage to the river ecosystem. When comparing small and large hydropower plants, small hydropower plants have a greater negative impact per megawatt of electricity produced $[5,6]$.

For the above reasons, trends in the construction of conventional hydropower plants should be directed towards modernisation and streamlining of the work of large hydropower plants rather than the massive construction of small hydropower plants. Small hydropower plants should be designed primarily for those areas where the population density is sparse and where it is not efficient to draw electricity through power lines [7, 8].

These claims are also confirmed by a study carried out in Norway, which compared the environmental impact of small and large hydropower plants [9]. However, deciding on the direction of development is often not just a question of assessing the effectiveness or environmental impact, but also of other circumstances, such as political priorities. However, at present, the attenuation of the proactive construction of small hydropower plants can be seen, which can be considered a good signal to stabilise the situation $[10,11]$. The main environmental consequences of hydropower plants can be classified by their impact on the aquatic ecosystem [12].

By damming the stream, the natural flow in the riverbed is disrupted, which results in degradation of the bottom and banks or erosion. Dams disrupt the flow, worsen the quality of water, block the movement of animals and sediments in the river, destroy fish habitats and prevent the natural migration of fish, with even built fish paths not alleviating the issue [13].

However, there are other methods than those mentioned above that make it possible to obtain electricity from renewable sources. In our study, we search for alternatives to building small hydropower plants. One method is to install small floating devices. Such devices are suitable for rivers with small slopes and low flow velocities, with research in this area already under way. An example is the floating hydroelectric power plant on the Mura River in Hungary. This power plant achieves an electrical output of $5-10 \mathrm{~kW}$. We focus on the possibility of increasing the efficiency of floating equipment by various methods of technical improvement [14]. 
We present the research and development of the optimal construction of a small floating hydroelectric power plant by theoretical analysis and subsequent conceptual design of the most suitable variant. As a computational fluid dynamics (CFD) software tool, the Autodesk Simulation CFD 2016 system is used in this project for theoretical analyses of fluid flow, flow around, free surface properties, and body motions in water. The provided CFD simulations allowed us to model the dynamics of fluid flow in configurations that are calculated on the base of the Navier-Stokes equations implemented in the software and solving the numerical problem using the finite volume method [15].

Meaning of words Optimization and Optimum in this paper: in general they stand for a process and its result the goal of which is to find the best technical idea and solution giving the highest possible performance of the plant but also fulfilling several different requirements, e.g. issues concerning the river flow conditions, the river bank infrastructure, the possible environmental impacts, the protection of the wheels, the complexity of manufacturing the plant, the economic profitability, etc.

So, they are not used in a purely mathematical meaning, rather in technical.

The aim of this study is to identify the optimal geometry and construction of a small floating hydroelectric power plant intended for the Slovak section of the Danube and the lower part of the Váh River. The following partial tasks are solved using a series of theoretical calculations, analyses, and simulations:

- Optimal shape of the water wheel and its size;

- Optimal shape of the water wheel blades;

- Optimal number of blades;

- Optimal location of the hydropower plant with respect to the riverbank and flow depth;

- Optimal mutual placement of several water wheels by comparing the effectiveness of different layouts;

- Optimal shape of the water corridor and water supply to the water wheels;

- Use of water flow barriers and rectifiers to increase the efficiency of the water wheel;

- Possibility of using the lower boundary of the water corridor;

- Optimal water wheel rotation speed.

The following general procedure was used to solve the individual sub-tasks:

- $\quad$ Drawing up various alternatives;

- Theoretical comparison of the effectiveness of the various alternatives;

- Identification of two or several of the most efficient alternatives based on theoretical calculations. 


\section{Theoretical Background}

Based on the nature of the discussed flows, the floating power plant under investigation is a free surface, hydrokinetic type that uses purely the kinetic energy of water flow. Classic water wheels are the most suitable for such electricity production in the difficult conditions of our rivers, especially when the economic aspect is also considered.

A similar single-wheel floating hydroelectric power plant installed on the Mura River in Hungary achieves an average overall efficiency of 55\% [14]. This object was considered a model at the beginning of the development and a higher resulting efficiency level was set as a target. When determining the input parameters of the tunnel flow and the initial dimensions of the wheels, the possible main dimensions of the double-wheel bearing floating pontoon were also considered and their parameters are given in Table 1.

Table 1

Main dimensions of a double-float pontoon

\begin{tabular}{cccc}
\hline $\mathbf{L}[\mathbf{m}]$ & $\mathbf{B}[\mathbf{m}]$ & $\mathbf{H}[\mathbf{m}]$ & $\mathbf{T}[\mathbf{m}]$ \\
\hline $\max .40$ & 11.4 & 3.0 & 2.0 \\
\hline
\end{tabular}

where:

- $\quad \mathrm{L}[\mathrm{m}]$ is the length of a double-float pontoon;

- $\quad$ B $[\mathrm{m}]$ is the breadth of a double-float pontoon;

- $\quad \mathrm{H}[\mathrm{m}]$ is the height of a double-float pontoon;

- $\quad \mathrm{T}[\mathrm{m}]$ is the draught of a double-float pontoon.

The rectangular cross-sectional area of the tunnel is calculated by:

$S=b \cdot t\left[m^{2}\right]$,

where:

- $\quad b[\mathrm{~m}]$ is the width of the rectangular section of the tunnel;

- $\quad t[m]$ is the depth of the rectangular section of the tunnel.

The volume flow rate is calculated by:

$Q=S \cdot v\left[m^{3} \cdot s^{-1}\right]$,

where:

- $\quad v\left[m \cdot s^{-1}\right]$ is the flow velocity.

The mass flow rate is calculated by: 
$q=\rho \cdot Q\left[\mathrm{~kg} \cdot \mathrm{s}^{-1}\right]$,

where:

- $\quad \rho\left[\mathrm{kg} \cdot \mathrm{m}^{-3}\right]$ is the density of water.

The maximum theoretical power of the water flow kinetic energy is calculated by:

$P_{W}=\frac{1}{2} \cdot q \cdot v^{2}[k W]$.

The hydraulic power of the power plant is determined by:

$P_{H}=P_{W} \cdot \eta_{H}[k W]$,

where:

- $\eta_{H}[-]$ is the hydraulic efficiency of the wheel and tunnel.

The mechanical power of the power plant is determined by:

$P_{M}=P_{H} \cdot \eta_{M}[k W]$,

where:

- $\quad \eta_{M}[-]$ is the mechanical efficiency of the bearings and gears.

The delivered electric power of the power plant is determined by:

$P_{E}=P_{M} \cdot \eta_{E}[k W]$,

where:

- $\quad \eta_{E}[-]$ is the electrical efficiency of the generator.

The overall efficiency of the hydropower plant is calculated by:

$$
\eta_{T}=\eta_{H} \cdot \eta_{M} \cdot \eta_{E}[-] .
$$

The equation used to estimate the output hydraulic power of a single hydrokinetic water wheel is:

$P_{0}=\frac{1}{2} \cdot \rho \cdot S \cdot C_{p} \cdot v^{a}[k W]$,

where:

- $\quad C_{p}[-]$ is the power coefficient.

However, determining the power coefficient $C_{p}$ is very difficult, and very different approaches are reported in the literature. In contrast, the use of a single wheel has been excluded during the development and this equation only has a very limited application for multiple wheels that interact with each other. 
In this development task, the hydraulic power was determined from the output values of the CFD analyses, which were the torques and angular velocities of the water wheels, by:

$P_{H}=M \cdot \omega[k W]$,

where:

- $\mathrm{M}[N m]$ is the hydrodynamic torque;

- $\quad \omega\left[\mathrm{rad} \cdot \mathrm{s}^{-1}\right]$ is the angular velocity.

From the hydraulic power value obtained, the hydraulic efficiency $\eta_{H}$ was calculated using Eq. (5). Other parameters, such as mechanical and electric power, can only be determined when the corresponding efficiencies are known. The efficiencies depend on the choice of other components of the power plant, on the bearing of the wheel shaft, on the transmission devices and on the electric current generator.

\section{Methods}

This study consists of the analysis of different configurations. The most common method that allows for computer modeling of flow is CFD. The principle and limitations of this method in relation to flow modeling have been addressed in several studies [16-18]. The results of modeling, as well as the time of their implementation, depend mainly on the number of elements (and nodes) and also on the quality of computer technology [19]. Computer-aided design software is used for the two- and three-dimensional design of floating power plant elements [20].

Five different versions of floating pontoons, from A to E (Figure 1), were designed and analysed by means of computer-aided design and CFD software (see example CFD results in Figures $1 \mathrm{f}$ and $3 \mathrm{c}$ ). The flow velocity properties inside the tunnels were considered in order to eliminate unfavourable shapes with high resistances (losses). Step-by-step, the pontoon versions with the greatest drag forces, the greatest flow decelerations, and the smallest mass flow (flux) between pontoons were eliminated. For comparable values, "simpler" shapes with fewer water wheels have always had the advantage. 


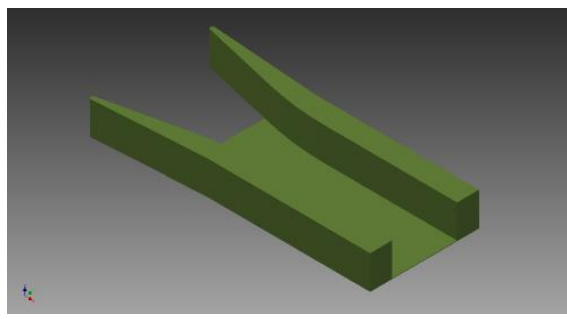

(a)

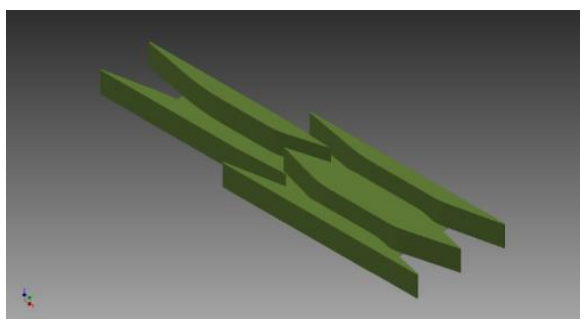

(c)

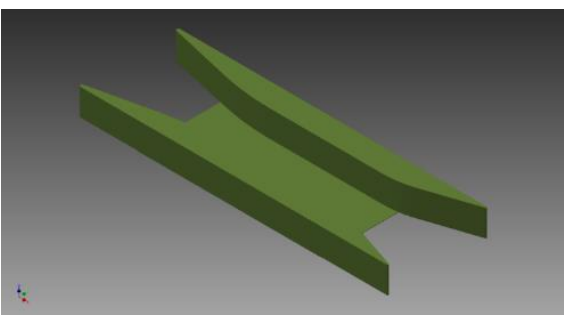

(b)

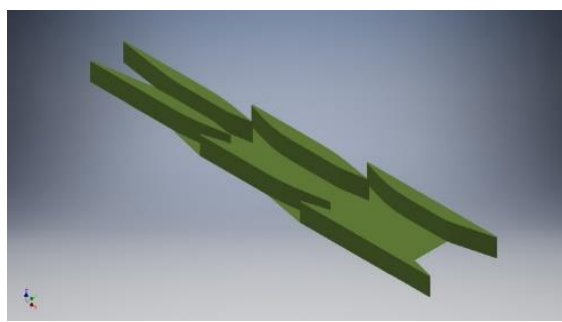

(d)

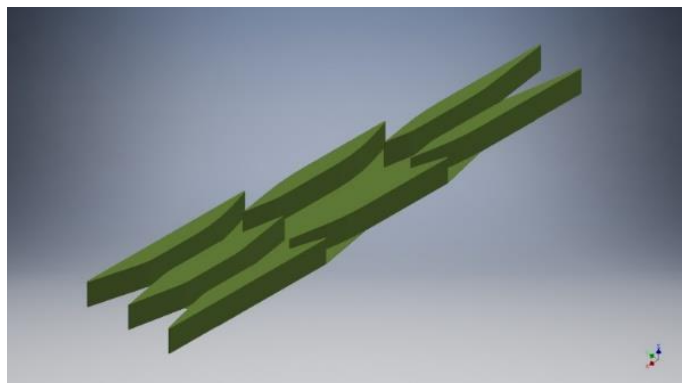

(e)

Figure 1

Different versions of the pontoons: (a) pontoon A, basic version of two floats/two wheels; (b) pontoon $\mathrm{B}$, improved version of two floats/two wheels; (c) pontoon C, five floats/three wheels; (d) pontoon D, six floats/three wheels; (e) pontoon E, seven floats/four wheels

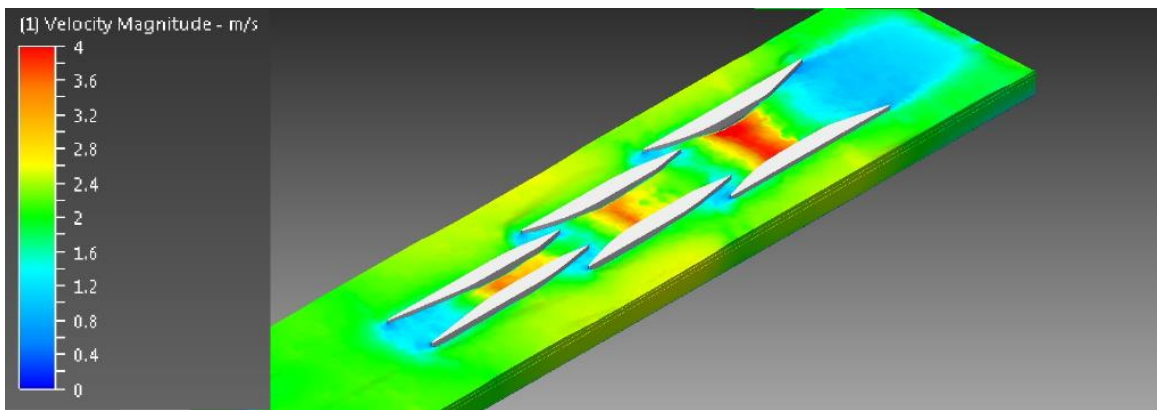

Figure 2

Example CFD output showing free surface flow velocities 
All preliminarily designed versions of the pontoons passed an optimisation CFD test, where three possible variations were examined:

- Pontoon open from below in between the floats;

- Pontoon from below closed by a flat bottom between floats;

- Pontoon closed with a specially shaped inner bottom.

Flow analysis was performed for all versions from A to E. Figure 3 shows pontoon B in more detail.

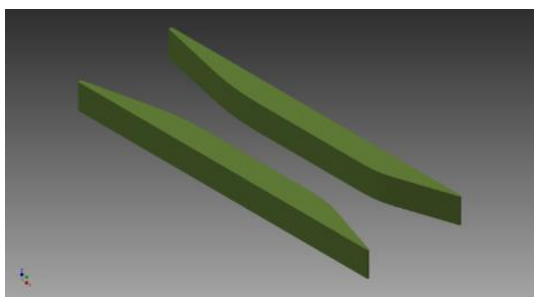

(a)

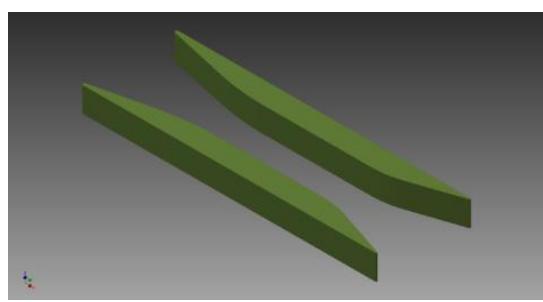

(b)

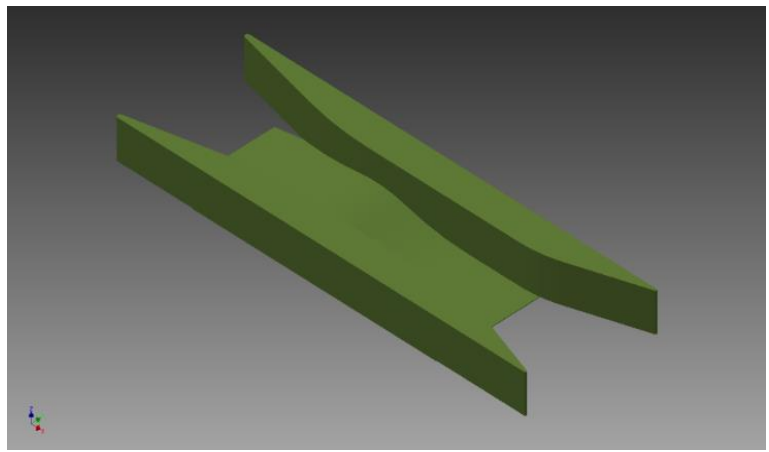

(c)

Figure 3

An example flow analysis for pontoon B: (a) pontoon open at the bottom between the floats; (b) pontoon closed from below by a flat bottom; (c) pontoon closed with the shaped inner bottom surface

CFD analysis shows that the most suitable design is the pontoon provided by a flat bottom between the floats. During the consideration also other factors have been taken into account like the influence of the river bed on the induced turbulences or the protection of the rotating parts against floating objects, etc.

In the next step, the interaction of water wheels (basic version) with individual floating pontoons was tested by a simplified CFD analysis. The analysis was performed in a relatively short time for all versions from A to E, with pontoon D presented in Figure 4. 


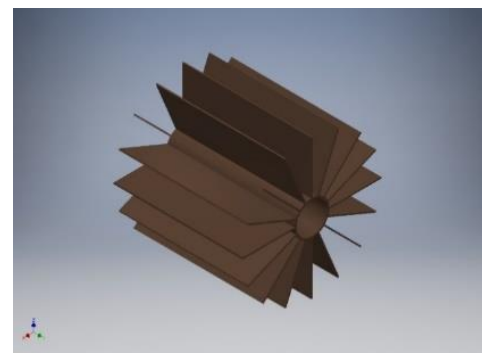

(a)

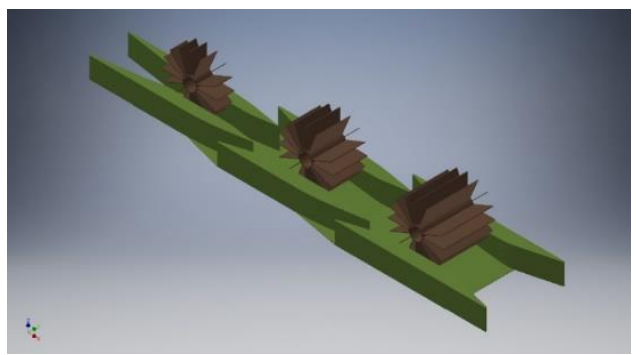

(b)

Figure 4

Interaction of water wheels with pontoon D. (a) Three-dimensional model of the basic version of the wheel. (b) Three-dimensional model of the pontoon/wheel assembly

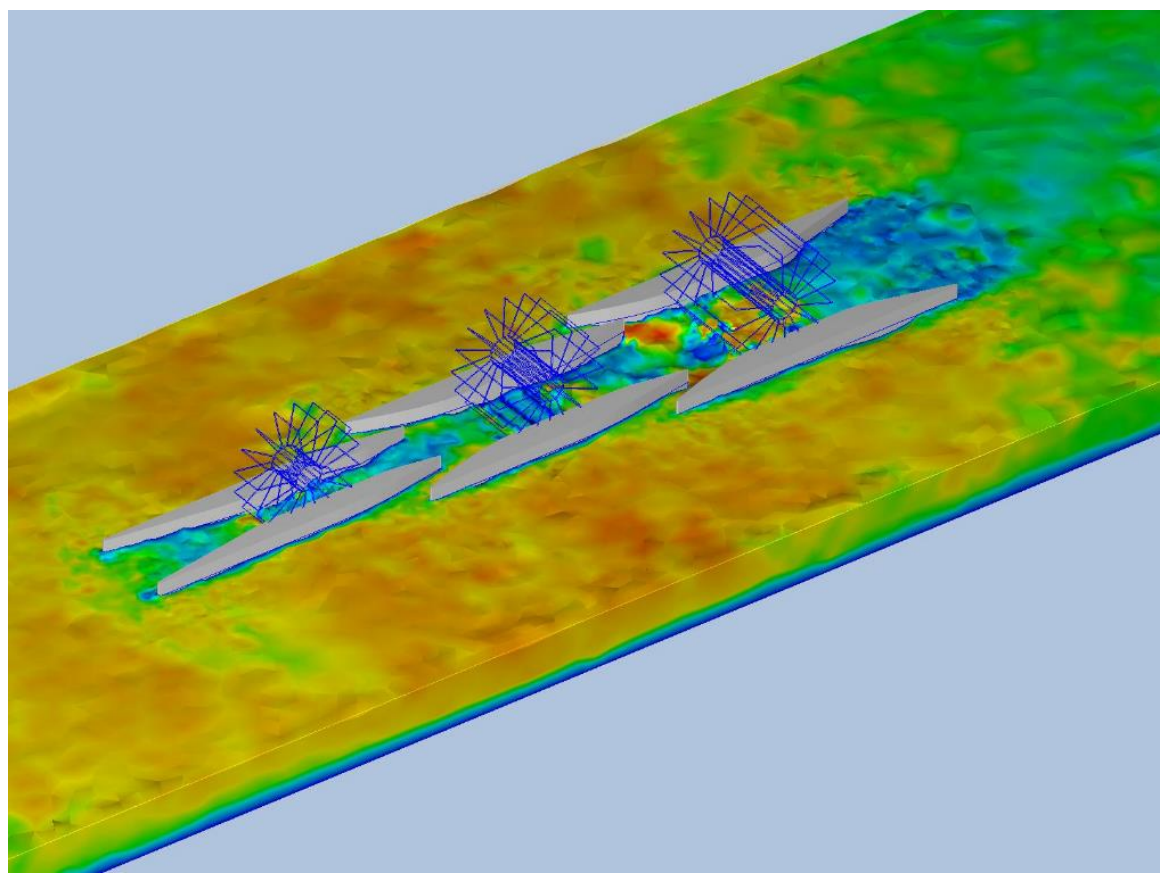

(c)

Figure 5

Example CFD output showing free surface flow pattern

As rotating water wheels have appeared in the CFD domain to work together with the stationary pontoons, the most important selection criteria became the generated hydrodynamic torque and the angular velocity of the wheels. Based on the results of these CFD analyses, it was decided that further analysis and development would be limited to only pontoons B and D. The calculations also showed that the third row of wheels no longer had significant performance advantages. 
As on this basis and also from an economic point of view, the optimal number of wheels was set at two. As a result, version D was modified to a two-tier assembly and is now labelled as pontoon $\mathrm{F}$.

The computational domain and the solver of the Simulation CFD software were configured as follows:

- transient task with free water surface (multiphase),

- $\quad \mathrm{k}-\varepsilon$ turbulence model,

- tetrahedral mesh, mean size $50 \mathrm{~mm}$ in refined near areas, $250 \mathrm{~mm}$ in far areas,

- $\quad$ rotating regions surrounding the wheels.

Grid independence calculations particularly for this project have not been performed. Based on several previously analysed similar configurations it can be stated that the expected difference in resulting values would be in range $1-2 \%$, if the analysis was performed for a refined mesh with half-size elements. This is acceptable, the difference is less than the numerical error of the process.

The aim of the analysis was not to obtain exact absolute values of hydrodynamic quantities, but rather to confront relative values and optimize by comparison methods.

\section{Results}

The computational tunnel is a purely theoretical case of a channel open from above, having a rectangular cross-section of a sectional area identical with the cross-section of a solid filled wheel. In other words, the wheel completely fills the cross-section or is enclosed by the boundary surfaces of the computational volume (CFD domain). Such a domain is suitable for comparative analyses because the impact of the environmental factors is minimised.

\subsection{Water Wheel Optimisation and Analysis of Hydraulic Performance in Computational Tunnel}

Three optimisation steps were performed sequentially based on the comparative calculations and analyses. The size of the blades was determined by the depth of the water and the dimensions of the wheels determined the main dimensions of the pontoon. The number of blades was gradually increased until the maximum hydraulic power of the wheel was reached. The following versions of the water wheel were proposed as outputs: 
Version 1: Optimisation of the basic version of the wheel, with curved blades, used instead of straight ones (Figure 6). The radius of curvature and the number of blades were optimised based on the resulting hydrodynamic properties of the wheel.

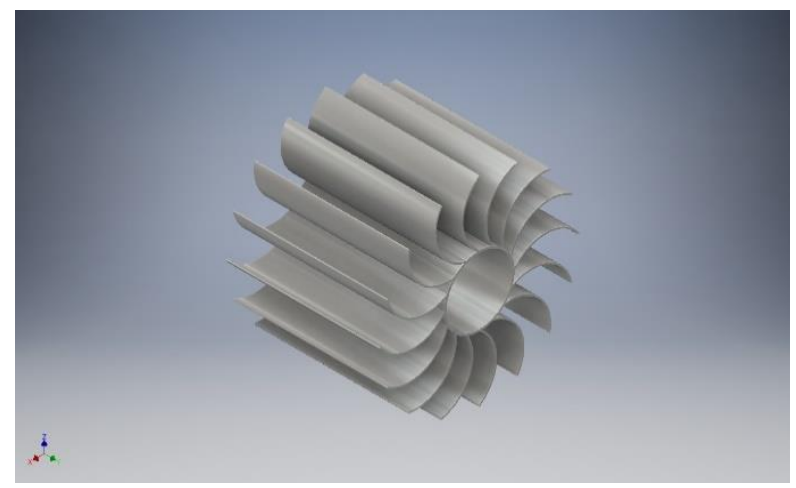

Figure 6

Water wheel version 1 with curved blades

Version 2: Results of the second step of the wheel optimisation. In order to achieve a smoother course of hydraulic pressures and torques, but also to reduce vibrations and possible resonant states of the wheel pairs, the wheel was divided into three mutually twisted "discs" (Figure 7).

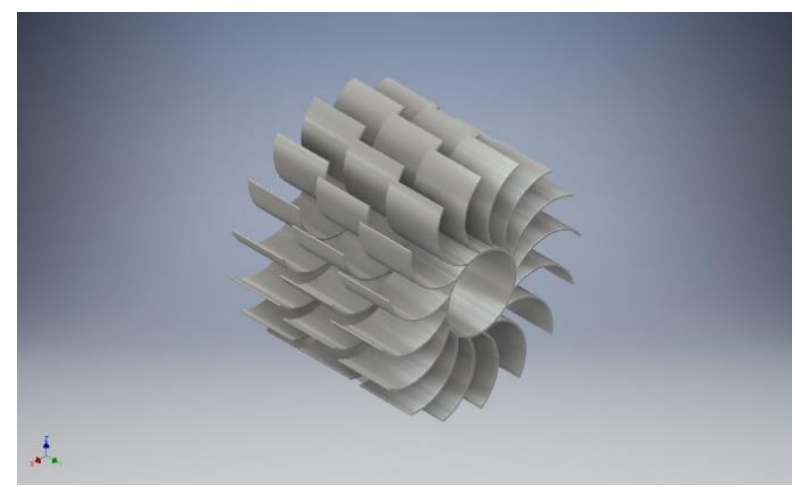

Figure 7

Water wheel version 2 with three mutually twisted discs

Version 3: The third step of the wheel optimisation. In order to eliminate significant axial flows of water between the blades and reduce the related losses, the individual discs were separated by thin circular plates (Figure 8). 


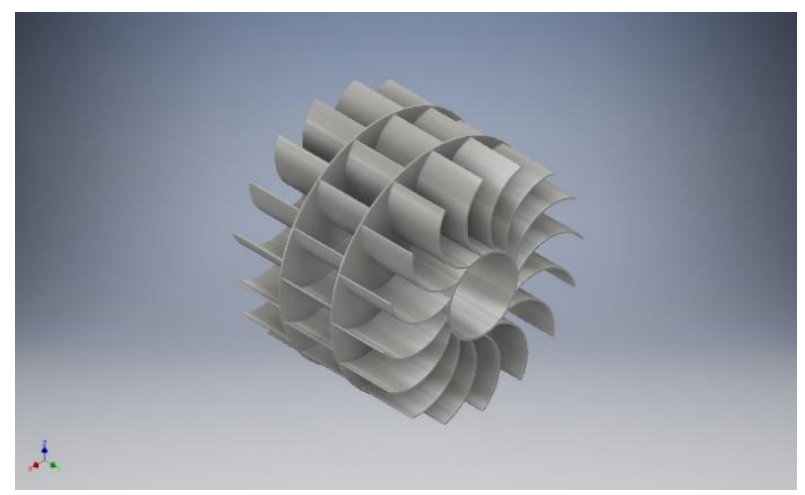

Figure 8

Water wheel version 3 with three twisted discs separated by thin plates

\subsection{Analysis of Hydraulic Power in the Computational Tunnel}

CFD simulations of the individual versions were performed for the same calculation tunnel with the same settings for water flow velocities of 2, 2.5, 3 and $3.5 \mathrm{~m} / \mathrm{s}$ (Figure 9).

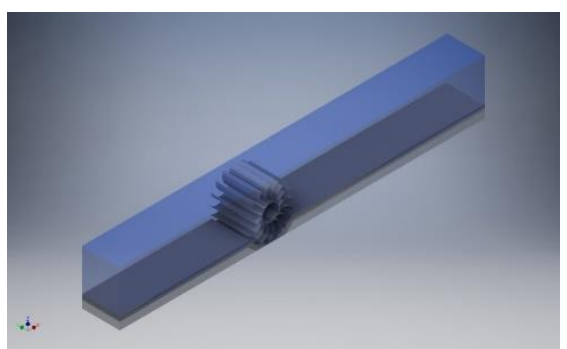

(a)

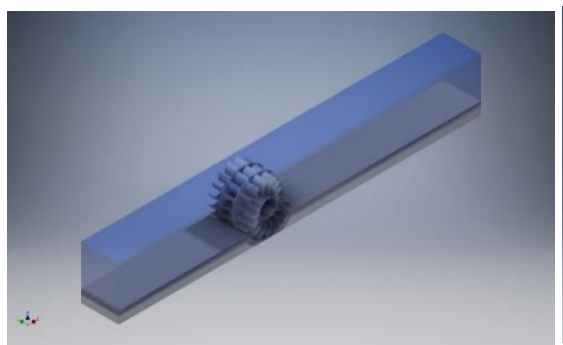

(c)

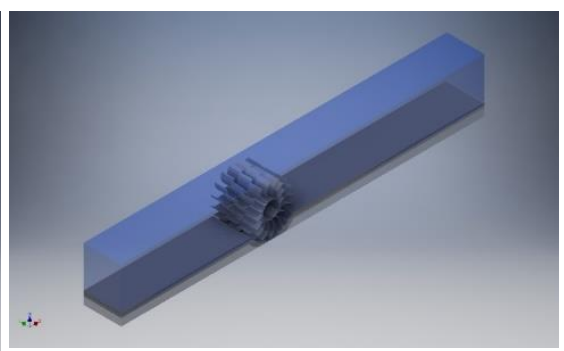

(b)

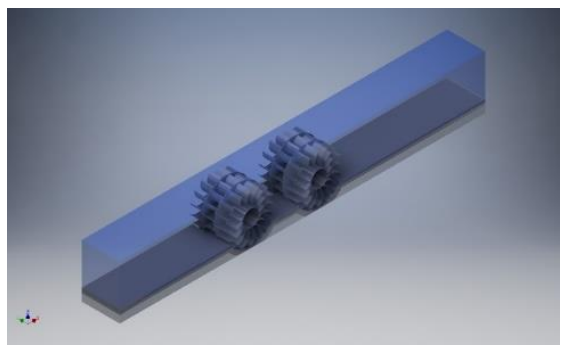

(d)

Figure 9

CFD analyses of the three different kinds of blades in the tunnel: (a) wheel version 1; (b) wheel version 2; (c) wheel version 3; (d) two wheels of version 3 


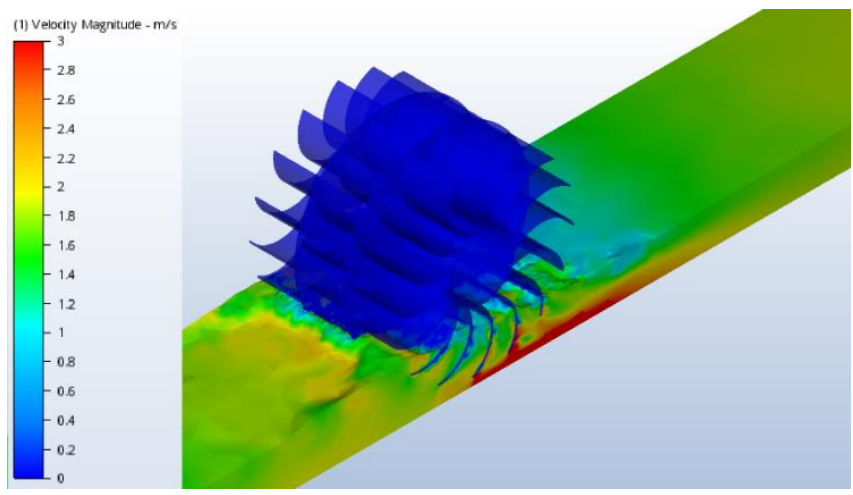

Figure 10

An example CFD output of flow velocities in a tunnel

\subsection{Geometrical Design of Floating Pontoons and Synergy Analysis}

The geometry of only two of the following types of pontoons was optimised, which were selected for further development in the previous optimisation steps (the flat bottom of the pontoons is not shown in the next figures).

Pontoon B: The floating pontoon of type B (Figure 11a) is a double-float construction, closed from below with a flat bottom. It is suitable for the installation of two identical water wheels in a row. It has one water inlet at the front and one outlet at the rear.

Pontoon F: Pontoon type F (Figure 11b) was created as a combination of pontoons B and D. It has four floats, is closed from below with a flat bottom, and is suitable for installing two water wheels of different widths in a row. It has one water inlet at the front, two side inlets, and one outlet at the rear.

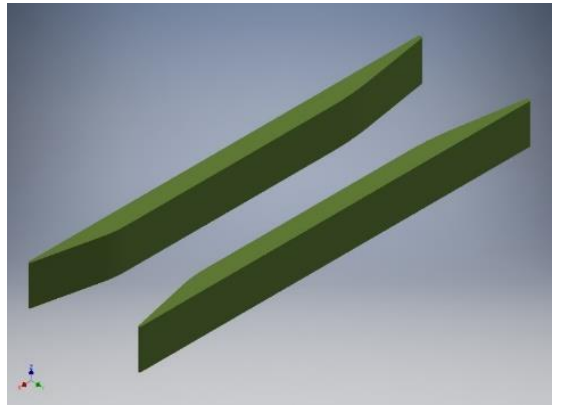

(a)

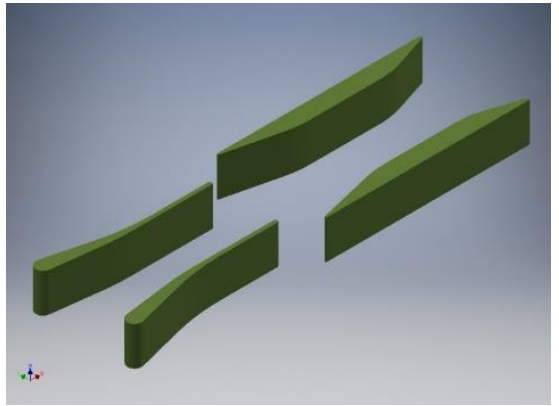

(b)

Figure 11

Computation models of pontoons (a) B and (b) F 
All in-depth CFD analyses of hydraulic performance were performed uniformly for a water flow velocity of $2 \mathrm{~m} / \mathrm{s}$. The aim of the calculations was to compare the performances and efficiencies of the two most promising arrangements of pontoons $\mathrm{B}$ and $\mathrm{F}$. Based on the previous results and considerations, two-tier-type arrangements were selected and equipped with pairs of version 3 water wheels (Figure 12). In version F, the front wheel was made narrower to improve the lateral water supply to the rear wheel.

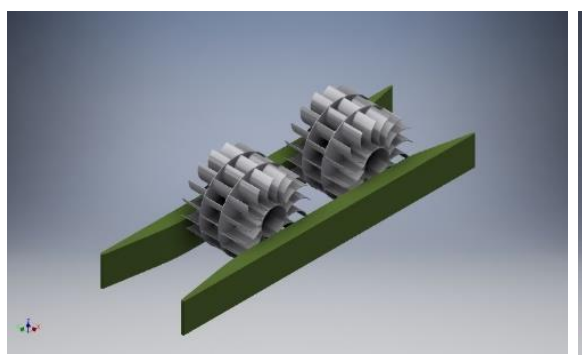

(a)

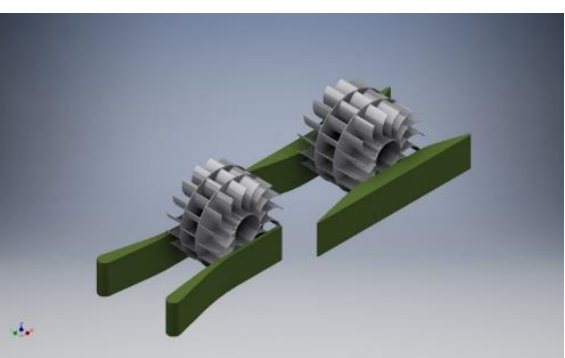

(b)

Figure 12

CFD models of different pontoons with version 3 wheels for pontoons (a) B and (b) F

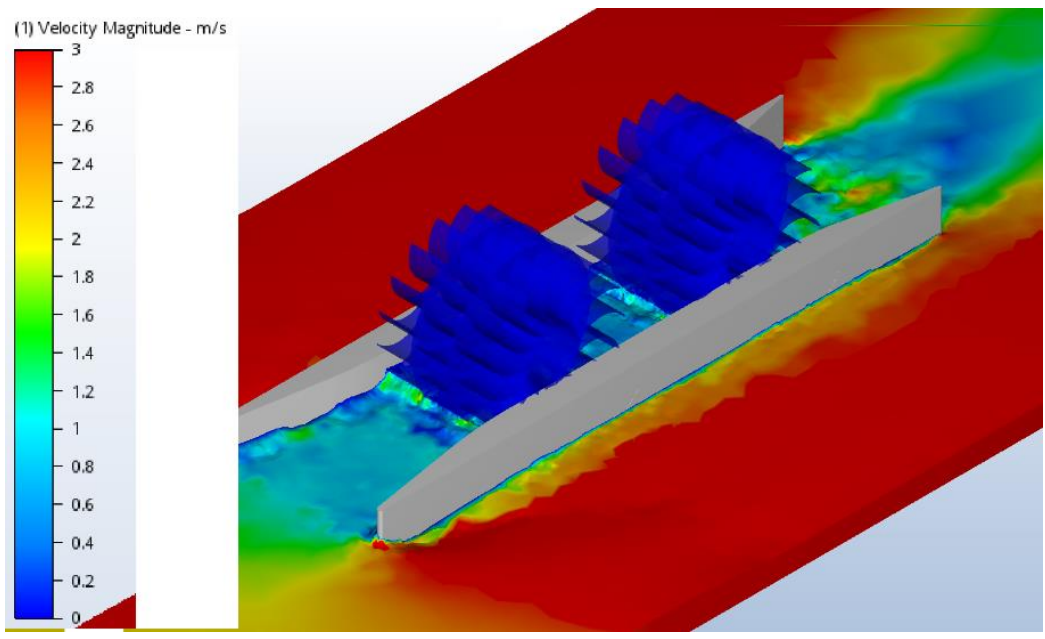

Figure 13

An example CFD output for flow velocities in the pontoon area 


\section{Discussion}

Based on the CFD analyses performed in the process of water wheel optimisation, a gradual increase in hydraulic performance was observed, the course of which is shown in Figure 14. A uniform water flow velocity of $2 \mathrm{~m} / \mathrm{s}$ was used in all calculations.

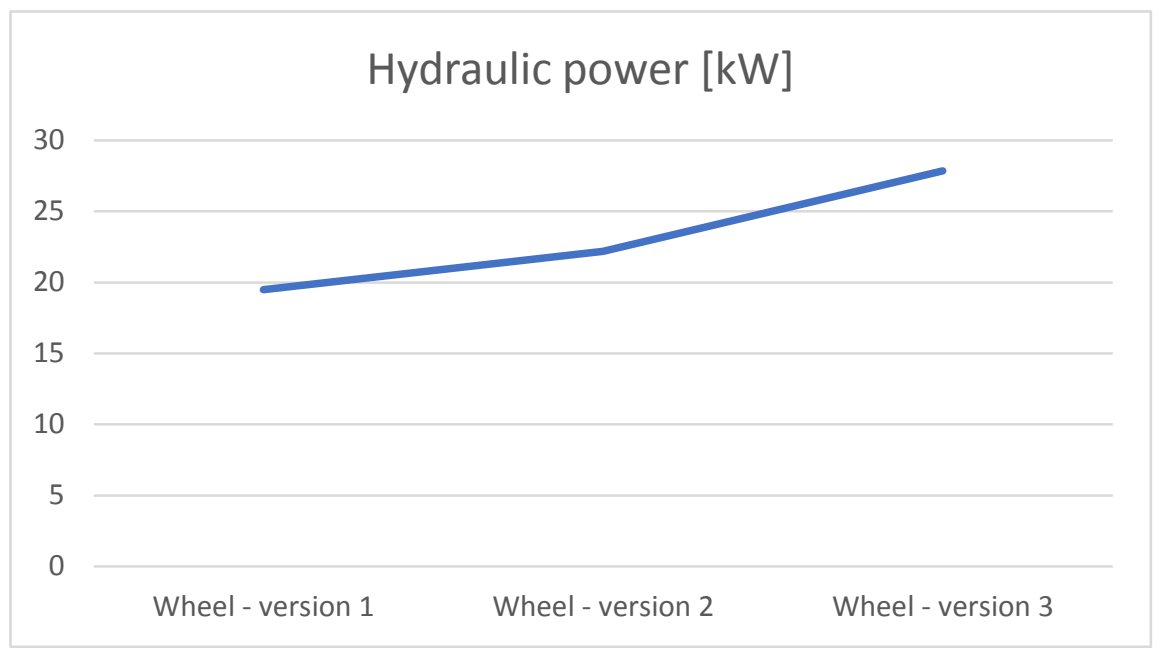

Figure 10

Increase of hydraulic power depending on degree of wheel optimisation

Figure 14 shows that wheel version 2 has an increased hydraulic power compared to wheel version 1 by $16 \%$ and to the wheel version 3 by up to $46 \%$.

CFD analyses were also performed to determine the dependency of hydraulic power on the velocity of water flow (Figure 15). Simplified CFD analyses were performed in a theoretical calculation tunnel for a single wheel assembly with the most efficient geometry of wheel version 3 . 


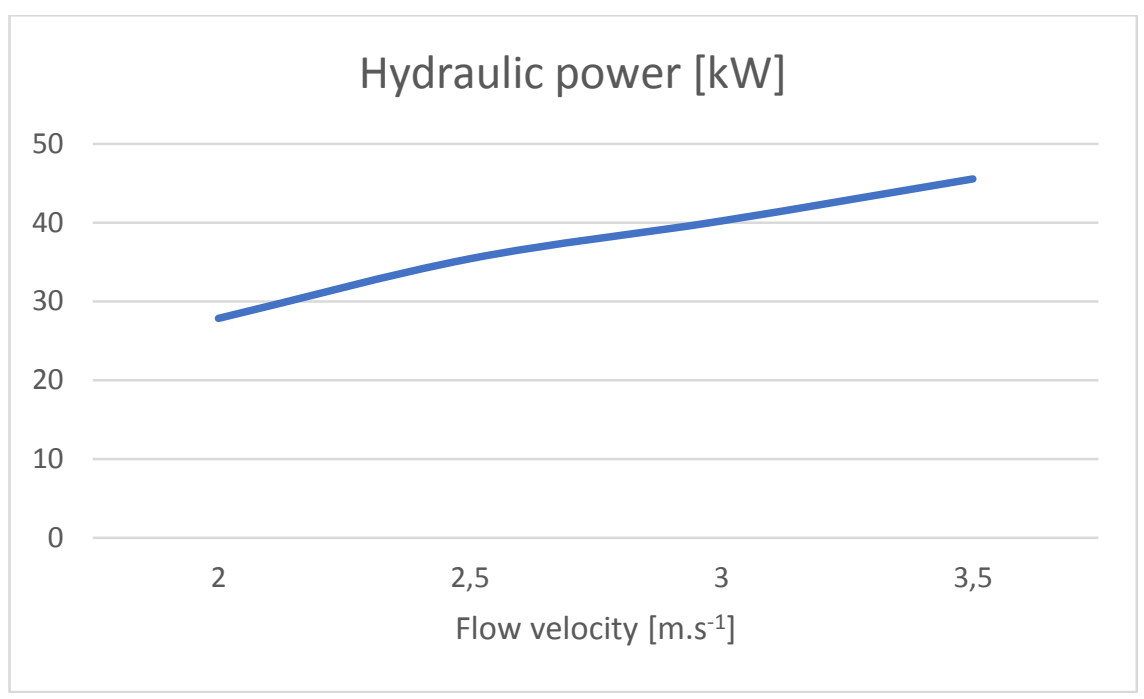

Figure 15

Dependence of hydraulic power on flow velocity

From Figure 15, it is clear that by increasing the flow velocity from the base value $(2 \mathrm{~m} / \mathrm{s})$, the increase of hydraulic power does not follow closely the increase of kinetic energy of the water flow, i.e., the hydraulic efficiency of the assembly decreases. Such a reduction, especially at higher speeds, could also be affected by the applied calculation method (simplified domain); however, these results had no effect on the further development process. For the final evaluation, more accurate analyses were performed and velocities higher than $2.5 \mathrm{~m} / \mathrm{s}$ were not examined (they are not realistic at the chosen geographical locations).

Based on the results of the in-depth CFD analyses of the plant assembly, the highest hydraulic power and thus the best hydraulic efficiency was achieved by pontoon $\mathrm{F}$ with a pair of version 3 wheels. The average value of the calculated hydraulic power reached $P_{H}=59.5 \mathrm{~kW}$. Analyses were performed for a flow velocity of $2 \mathrm{~m} / \mathrm{s}$. This value was chosen as the characteristic velocity realistically achievable in the target locations of the concerned sections of the Danube and the Váh River.

The total hydraulic efficiency of a small floating power plant was determined from the dimensional parameters of the wheel/pontoon system and from the physical properties of the water flow using Eqs. (1) to (5).

For input values of $P_{H}=59.5 \mathrm{~kW}, b=10.0 \mathrm{~m}, t=2.0 \mathrm{~m}, \rho=1000.0 \mathrm{~kg} / \mathrm{m}^{3}$ and $v=2 \mathrm{~m} / \mathrm{s}$, the physical quantities listed in Table 2 were determined successively and the resulting total hydraulic efficiency is 0.744 . 
Table 2

Calculation parameters and hydraulic efficiency of power plant

\begin{tabular}{llllll}
\hline $\mathbf{S}\left[\mathbf{m}^{\mathbf{2}}\right]$ & $\mathbf{Q}\left[\mathbf{m}^{\mathbf{3}} / \mathbf{s}\right]$ & $\mathbf{q}[\mathbf{k g} / \mathbf{s}]$ & $\mathbf{P}_{\mathbf{W}}[\mathbf{k W}]$ & $\mathbf{P}_{\mathbf{H}}[\mathbf{k W}]$ & $\boldsymbol{\eta}_{\mathbf{H}}[-]$ \\
\hline 20.00 & 40.0 & 40000.00 & 80.0 & 59.5 & 0.744
\end{tabular}

where:

- $\quad \mathrm{S}\left[\mathrm{m}^{2}\right]$ is the cross-sectional area of the tunnel;

- $\quad \mathrm{Q}\left[\mathrm{m}^{3} / \mathrm{s}\right]$ is the volume flow rate;

- $\quad \mathrm{q}[\mathrm{kg} / \mathrm{s}]$ is the mass flow rate;

- $\quad \mathrm{P}_{\mathrm{W}}[\mathrm{kW}]$ is the theoretical power of the water flow;

- $\quad \mathrm{P}_{\mathrm{H}}[\mathrm{kW}]$ is the hydraulic power of the power plant;

- $\quad \eta_{\mathrm{H}}[-]$ is the total hydraulic efficiency.

Based on the total hydraulic efficiency obtained and the estimated values of mechanical and electrical efficiency, the electric power and overall efficiency of the power plant were further determined by means of Eqs. (6) to (8).

The chosen values for the theoretical efficiencies were:

- $\eta_{M}=0.96$ - this mechanical efficiency is achievable with a direct generator drive;

- $\eta_{E}=0.95$ - most of the current generators achieve such electrical efficiency by default.

The calculation of the usable theoretical energy of water flow and the electric power of the power plant was performed for the flow velocity range of 1.75-2.50 $\mathrm{m} / \mathrm{s}$, assuming that the hydraulic efficiency does not change significantly in the calculation interval. The results are shown in Table 3 and the plots are presented in Figure 16.

Table 3

Calculation parameters and theoretical electric power of power plant

\begin{tabular}{llllll}
\hline $\mathbf{v}[\mathbf{m} / \mathbf{s}]$ & $\mathbf{Q}\left[\mathbf{m}^{\mathbf{3}} / \mathbf{s}\right]$ & $\mathbf{q}[\mathbf{k g} / \mathbf{s}]$ & $\mathbf{P}_{\mathbf{W}}[\mathbf{k W}]$ & $\mathbf{P}_{\mathbf{H}}[\mathbf{k W}]$ & $\mathbf{P}_{\mathbf{E}}[\mathbf{k W}]$ \\
\hline 1.75 & 35.0 & 35000.00 & 53.6 & 39.9 & 36.4 \\
2.00 & 40.0 & 40000.00 & 80.0 & 59.5 & 54.3 \\
2.25 & 45.0 & 45000.00 & 113.9 & 84.8 & 77.3 \\
2.50 & 50.0 & 50000.00 & 156.3 & 116.3 & 106.0 \\
\hline
\end{tabular}

where:

- $\quad \mathrm{v}[\mathrm{m} / \mathrm{s}]$ is the flow velocity;

- $\quad \mathrm{Q}\left[\mathrm{m}^{3} / \mathrm{s}\right]$ is the volume flow rate; 
- $\quad \mathrm{q}[\mathrm{kg} / \mathrm{s}]$ is the mass flow rate;

- $\quad \mathrm{P}_{\mathrm{W}}[\mathrm{kW}]$ is the theoretical power of the water flow;

- $\quad \mathrm{P}_{\mathrm{H}}[\mathrm{kW}]$ is the hydraulic power of the power plant;

- $\quad \mathrm{P}_{\mathrm{E}}[\mathrm{kW}]$ is the delivered electric power of the floating plant.

The previous analyses and considerations result in a value of 0.68 for the total efficiency $\eta_{\mathrm{T}}$, while based on Figure 15 (single-stage arrangement in a computational tunnel with a simplified analysis), it is very likely that the hydraulic efficiency will decrease at higher speeds.

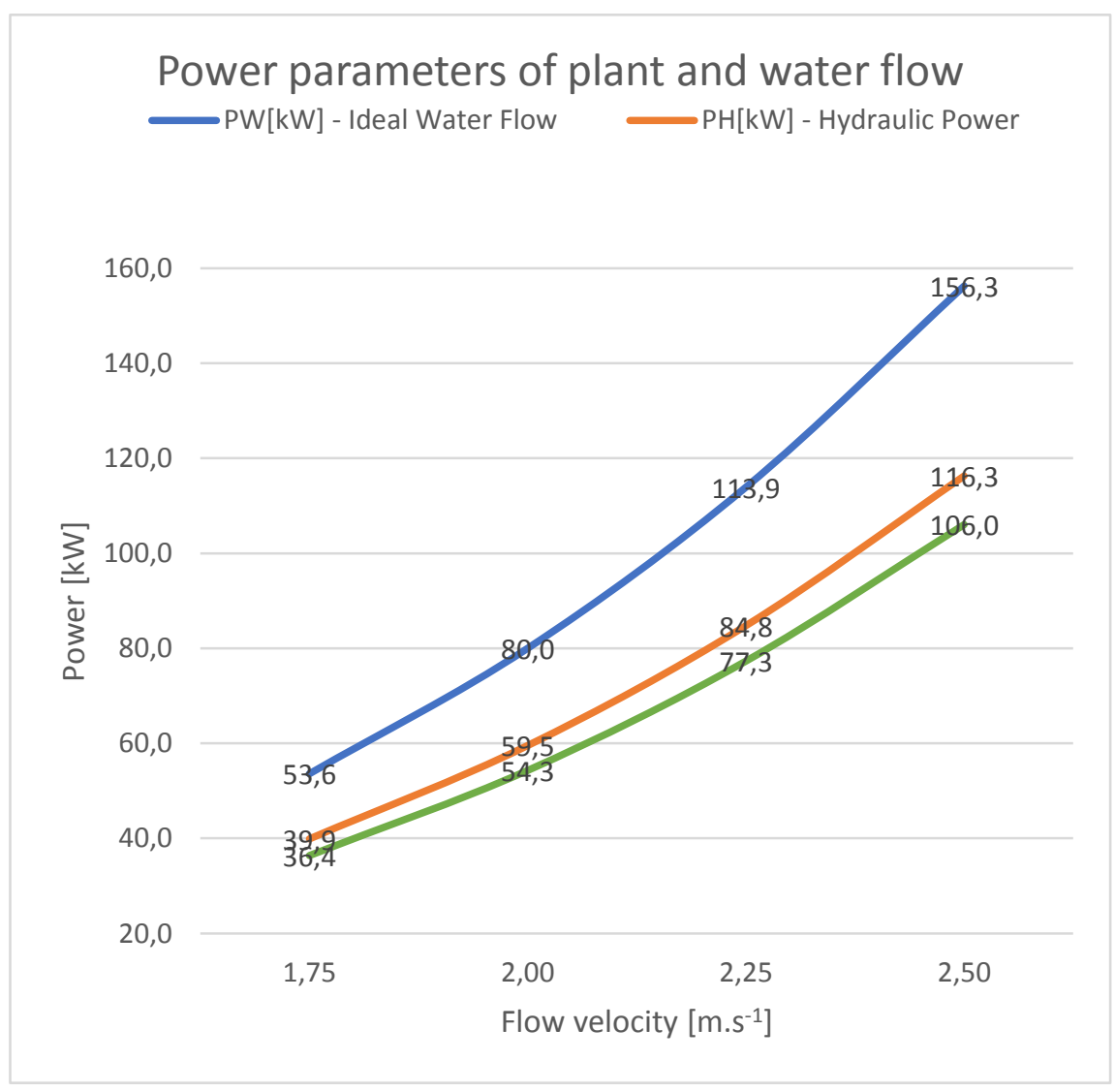

Figure 16

Dependence of hydraulic and electric power on water flow velocity

Based on the best results of the optimisation process, a conceptual design of a new hybrid power generation plant was developed using the already examined parameters and dimensions. To maximise the supplied electric power and the use 
of free space on the pontoon, it was proposed to supplement the equipment of the floating power plant as follows:

- Creating a light roof surface with an area of $\sim 300 \mathrm{~m}^{2}$ for placement of photovoltaic foils with a nominal output of $50 \mathrm{~kW}$;

- Installation of two wind generators in a suitable place above the roof with a nominal power of $8 \mathrm{~kW}$.

These sources of electricity will be sufficient to supply the operating and auxiliary systems of the pontoon with energy and thus will not burden the main generators. In the next steps of development, we propose to examine and implement the following measures for the construction of the hydroelectric power plant:

- Reduction of frictional resistance on the inner walls of the pontoon;

- Improving the water supply through the side inlets of pontoons;

- Further optimisation of the water wheel and the shape of its blades.

By implementing such measures, we can estimate that a $10 \%$ increase in the delivered electric power of the hydropower plant could be achieved. The planned model tests were not performed yet, but on the basis of the signed optimization, a similar functional power plant with a water wheel on the Mura River was built.

\section{Conclusions}

The results of the optimisation process confirm that it is possible to build up a floating small power plant using "classic" water wheels with higher efficiency. Compared to the exemplary single-tier type, which operates with 55\% efficiency, the optimised type F should actually reach over 68\% (after further optimisation steps). This significant increase was achieved with the following characteristics:

- Optimised pontoon shape, closed tunnel from below - even though the viscous resistance of the tunnel increases, the overall performance is improved because the water flow does not have the possibility to bypass the wheel from below;

- Optimised wheel geometry, shape, and arrangement of the blades special shaping and division prevented possible transverse flow in front of the blades and managed to achieve a smoother run along with reducing the susceptibility to get in "oscillating states" in CFD simulations when working in pairs;

- $\quad$ Two-tier wheel arrangement - the performed CFD analyses showed that with a single-tier arrangement it was no longer possible to significantly increase the efficiency, in the optimisation stage we chose the two-tier assembly. However, a simple doubling of the wheels would not bring the desired effect, due to the slowing down of the water flow in the tunnel with respect to the surrounding river flow. Therefore, it was necessary to specially shape the water wheels, the floating pontoon, and the tunnels; 
- $\quad$ Supply of "fresh" water from the side of the pontoon to the rear wheel calculations have clearly shown the advantage of side inlets on the pontoons. Where they were not used, the flow gradually slowed down and the simulation also showed a lack of water in the space between the two wheels (in extreme cases, oscillating states also occurred).

CFD analyses performed in the last phase were at the limit of the software's capabilities, were very demanding on the computing power of the hardware, and in some cases showed some instability. Therefore, all cases were analysed multiple times, if it was reasonable.

\section{Acknowledgement}

This research was funded by Institutional research of the Grant system of the Faculty of Operation and Economics of Transport and Communications, University of Zilina. This research is also the result of the Project VEGA No. 1/0128/20: Research on the Economic Efficiency of Variant Transport Modes in the Car Transport in the Slovak Republic with Emphasis on Sustainability and Environmental Impact, Faculty of Operation and Economics of Transport and Communications, University of Zilina, 2020-2022.

\section{Conflicts of Interest}

The authors declare no conflict of interest.

\section{References}

[1] Dvorak, Z., Rehak, D., David, A. and Cekerevac, Z: Qualitative Approach to Environmental Risk Assessment in Transport. Int. J. Environ. Res. Public Health 2020, 17, Art. no. 5494

[2] Hecht, J. S., Lacombe, G., Arias, M. E. and Dang, T. D: Hydropower dams of the Mekong river basin: a review of their hydrological impacts. J. Hydrol. 2019, 568, 285-300

[3] Xie, X., Jiang, X., Zhang, T. and Huang, Z: Regional water footprints assessment for hydroelectricity generation in China. Renew. Energy. 2019, $138,316-325$

[4] Mekonnen, M. M., Gerbens-Leenes, P. W. and Hoekstra, A. Y: The consumptive water footprint of electricity and heat: a global assessment. Environ. Sci. J. Integr. Environ. Res.: Water. Res. Technol. 2015, 1, 3, 285 297

[5] Kibler, K. M. and Tullos, D. D: Cumulative biophysical impact of small and large hydropower development in Nu River, China. Water Resources Research, 2013, 49, 6, 3104-3118

[6] Tiago, G. L., Silvia dos Santos, I. F. and Barros, R. M: Cost estimate of small hydroelectric power plants based on the aspect factor. Renewable \& Sustainable Energy Reviews. 2017, 77, 229-238, DOI: 10.1016/j.rser.2017.03.134 
[7] Euractiv: Assessment of Small Hydropower Plant. Available online: https://euractiv.sk/section/voda/opinion/male-vodne-elektrarne-su-horsieako-velke-dokazov-je-dost (accessed on 10.12.2020)

[8] Nogueira, M. F. M., Lima, C. U. S. and Ribeiro, R. R. P: The use of small hydroelectric power plants in the Amazon. Renewable Energy. 1993, 3, 8, 907-911, DOI: https://doi.org/10.1016/0960-1481(93)90049-M

[9] Bakken, T. H., Sundt, H., Ruud, A. and Harby, A. Development of Small Versus Large Hydropower in Norway- Comparison of Environmental Impacts. Energy Procedia, 2012, 20, 185-199

[10] Aguilar, S., Louw, K. and Neville, K: IHA World Congress Bulletin. International Institute for Sustainable Development (IISD) and International Hydropower Association (IHA) 2011

[11] Bueno, E. O., Mello, C. R. and Alves, G. J: Evaporation from Camargos hydropower plant reservoir: water footprint characterization. Revista Brasileira de Recursos Hídricos, 2016, 21, 3, 570-575

[12] Mekonnen, M. M. and Hoekstra, A. Y: The water footprint of electricity from hydropower. Value of Water Research Report Series. 2011, 51, 36

[13] American Rivers: Hydropower and Climate Change. Available online: https://www.americanrivers.org/threats-solutions/energydevelopment/hydropower-climate-change/ (accessed on 12.12.2020)

[14] Kadar, P: Small Hydro Plant Development. International Conference on Renewable Energies and Power Quality. Cordoba, Spain, 8-10 April 2014

[15] Illes, L., Kalina, T., Jurkovic, M. and Luptak, V: Distributed Propulsion Systems for Shallow Draft Vessels. J. Mar. Sci. Eng. 2020, 8, 667

[16] Douglas, J. F., Gasiore, J. M., Swaffield, J. A. and Jack, L. B: Fluid Mechanics, $5^{\text {th }}$ ed.; Pearson: Harlow, UK, 2005

[17] Molnar, V: Computational Fluid Dynamics - Interdisciplinary Approach with CFD; University of Technology in Bratislava (STU): Bratislava, Slovakia, 2011

[18] Kudelas, D: Basic of Computer Flow Modelling and Visualization; Faculty of Mining, Ecology, Process Control and Geotechnologies: Kosice, Slovakia, 2017

[19] Mikušová, N., Stopka, O., Stopková, M. and Opettová, E. Use of simulation by modelling of conveyor belt contact forces. Open Engineering, 2020, 9, 1, 709-715, DOI: 10.1515/eng-2019-0070

[20] Castro, H., Putnik, G., Castro, A. and Fontana, R. D. B: Open Design initiatives: an evaluation of CAD Open Source Software. Procedia CIRP, 2019, 84, 1116-1119, DOI: https://doi.org/10.1016/j.procir.2019.08.001 